\title{
How does the spatial context shape conditions for car dependency? An analysis of the differences between and within regions in the Netherlands
}

\section{Jake Wiersma}

University of Amsterdam

jake.wiersma@planet.nl

\section{Thomas Straatemeier}

University of Amsterdam

TStraatemeier@goudappel.nl

\author{
Luca Bertolini \\ University of Amsterdam \\ L.Bertolini@uva.nl
}

\begin{abstract}
Adapting cities and region to facilitate car use is not only a technical issue. It has made society heavily car-dependent, increasing the vulnerability of society to adverse changes in social, economic, environmental, or other spheres. This paper analyzes how the spatial context shapes conditions for car dependency, specifically focusing on the case of the Netherlands. Our research shows that, except in the periphery of the country, most daily amenities are within walking or biking distance, both in cities as well as in suburban and rural areas. However, regarding accessibility to jobs, there is no competitive alternative to the car-even in central city areas, which provide many more travel choices. The differences are not only related to population density or land use within the city, as is often thought, but also to the position of the urban area in the regional spatial context (i.e., its location relative to other urban areas). The bicycle as an alternative transport mode to the car scores highest in monocentric urban regions and in the central areas of cities close to a coastline or a national border. Public transport scores highest in central areas of medium-sized cities in polycentric regions and satellite towns near big cities.
\end{abstract}

\section{Introduction}

Across the Western world, the spatial context of cities and regions has been adapted and shaped to facilitate daily car use since the 1950s (and even earlier in North America). The patterns of activities are spreading out as the locations of homes, jobs, and daily amenities are being pulled away from each other and redistributed along ever more extensive road networks. This process continues in the West and is picking up speed in other parts of the world. Adapting the spatial context to car use is not only a

Copyright 2015 Jake Wiersma, Luca Bertolini \& Thomas Straatemeier

http://dx.doi.org/10.5198/jtlu.2015.583

ISSN: 1938-7849 | Licensed under the Creative Commons Attribution - Noncommercial License 3.0

The Journal of Transport and Land Use is the official journal of the World Society for Transport and Land Use (WSTLUR) and is published and sponsored by the University of Minnesota Center for Transportation Studies. This paper is also published with sponsorship from WSTLUR and the Institutes of Transportation Studies at the University of California, Davis, and the University of California, Berkeley. 
technical issue. It also creates strong car dependency because, in such a tailor-made spatial context, other modes of transport cannot compete with the flexibility, comfort, and speed of the car (Harms 2008; Litman and Laube 2002; Litman and Steele 2011; Stradling 2007; Jeekel 2011; Sheller and Urry 2006).

Car dependency has risks. It makes society vulnerable to possible changes. It leaves users vulnerable to, for example, measures that might be required to address pressing environmental challenges (e.g., rising fuel prices as fossil fuels are replaced by renewable energy and subsidies are phased out or the introduction of a carbon tax to curb $\mathrm{CO}_{2}$ emissions). It is not certain how car ownership and usage would be affected, but current modeling scenarios predict higher costs - in some cases substantially higher (Jeekel 2013; Millard-Ball and Schipper 2011; Dennis and Urry 2009). Higher costs could threaten the operation of firms located in a heavily car-dependent spatial context, making it more expensive to nurture essential relationships— such as access to workers, suppliers, and customers. If the effect on individual firms is sufficiently broad and severe, the competitiveness of the entire local economy could suffer. The rising costs of car use may also negatively affect the livelihoods of households that, because of their location, rely on cars for access to essential everyday resources such as jobs and amenities. The aggregated effect could be substantial social exclusion.

Car dependency might also stand in the way of upcoming changes in travel preferences. The mobility solutions of the mid-20th century are not the norm anymore. Young people across the developed world no longer see car ownership as the ultimate status symbol. For them, alternative travel modes seem to be important (Kuhnimhof 2011), and a car-dependent spatial context might severely limit their freedom to travel and live as they want. Similar processes seem to be taking place in the business world. Certain types of firms seem to prefer certain spatial contexts — such as dense and diverse cities—because they provide more flexible and diverse connection choices to employees, suppliers, and clients (Florida, 2010) than the car alone cannot offer.

Therefore, the risk of car dependency is that we make ourselves vulnerable to a range of possibleor even likely — changes in environmental, economic, and social spheres. These changes might make a shift to other transportation means desirable or even necessary. The underlying question is whether the spatial context of our cities and regions has become, or would become, an obstacle to making the required and desired changes in the way we travel in our daily lives.

This question is not adequately addressed in the existing literature, and our contribution seeks to fill this knowledge gap. The central research question is as follows: How does the spatial context of cities and regions shape conditions for car dependency?

In order to answer this question, we first examine the drivers and operationalization of car dependency in relation to the spatial context; then we describe the case study and introduce methods to determine the extent of car dependency. Next, we present the research results and move on to the conclusions and recommendations. In closing, the limitations of our study, research proposals, and policy implications are shared.

\section{Car dependency: definition, drivers, and operationalization}

\subsection{Car dependency defined}

Car dependency has principally been described and analyzed by North American and Australian authors. According to Newman and Kenworthy (1999), car dependency occurs when a city or area of a city assumes automobile use as the dominant imperative in its decisions on transportation, infrastructure and land use. Kenworthy and Laube (1999) studied 32 large cities worldwide on the car dependency of their inhabitants, comparing car ownership and car use with the use of public transport, and related this to land use characteristics. A problem with these kinds of studies - as Jeekel (2013), based 
on Gorham (2002) points out-is that when car dependency is defined in terms of car ownership or car use, the concept of "dependency" is not clarified. Travel behavior is not necessarily related to car dependency. Sometimes people choose to use a car, although alternative transport modes are available (i.e., they are not "dependent" on the car). Jeekel (2013) further distinguishes real (objective) car dependency from emotional (subjective) car dependency. Subjective car dependency can be a matter of habit, or of lack of information about alternative transport modes, but objective car dependency is simply having no acceptable alternative in terms of travel time and costs. This distinction is important, because in light of the discussion on the risks of car dependency in the introduction, it is the availability of alternatives that matters, more so than whether or not these alternatives are used. Following Jeekel (2013) we thus define car dependency as the lack of an adequate transport mode alternative (due to substantially higher time, effort, financial cost factors).

\subsection{Drivers of car dependency}

In several early studies — for example, Kenworthy and Laube (1999), Newman (1996), and Tayal et al. (2001) — car dependency is related to general spatial characteristics such as land-use density and length of freeways. More recent studies see car dependency more holistically as being part of a mobile lifestyle, which has become dominant in Western society (Steer Davies Gleave 2005; Brindle 2003; Jeekel 2013; Harms 2008). This lifestyle is being characterized by complex mobility patterns, multi-purpose trips, and tight time schedules. Jeekel (2013) foresees that Dutch society as a whole is becoming more car dependent as a result of this. Following Beck (1992) and Sennett (2006), he distinguishes between the first and second phases of modernity. The first phase, now completed, relates to the development of the nation state, with stable institutions, lifelong jobs, and relatively predictable mobility patterns. This phase led to more mobility as a consequence of the spatial dispersion of activities and social differentiation within society. The second phase of modernity, still under way, describes the globalization of the economy, more complex life and work arrangements and mobility patterns, and less stable travel patterns. The complex arrangements of modern life require flexibility and, at the same time, punctuality, as well as what Kaufmann et al. (2004) call "motility" — the individual capacity to move in different directions at different times and to partake in different activities. Jeekel (2013) sees the car as a rational answer to this required motility.

Yet Urry (2004) doesn't see the use of cars as simply a rational answer to societal needs that have arisen independently. He argues that automobility "reconfigures urban life." The urban environment built for the convenience of the car has unbundled the territorialities of home, work, business, and leisure that have historically been closely integrated (Urry 2004). Automobility is therefore not just an effect but also a cause of societal changes. Similarly, Handy (1993) explores how the automobile has indirectly led to dramatic changes in patterns of accessibility to retail and service activity within metropolitan regions, resulting in a "cycle of dependence." Current developments in the Western world illustrate this. In several domains, the traditional close-knit spatial distribution of amenities is disappearing. Schools are being concentrated at new locations in order to share facilities and staff; concentrated large-scale retail centers offer more choice for the customers and reduce operational costs. In other domains, such as health, increasing specialization also requires more trips to multiple destinations. These developments need not result automatically in car dependency. But the demands of accessibility by car and the need for parking space in most cases has resulted in locating new facilities near highways in the periphery of cities, which are difficult to reach with alternative transport modes.

In conclusion, societal forces have produced increasingly more complex mobility needs, and the car has emerged as the dominant answer to these needs. However, the ensuing adaptation of the spatial context to the needs of the car turned the car into the only possible mode choice. This process is illustrated in Figure 1: 


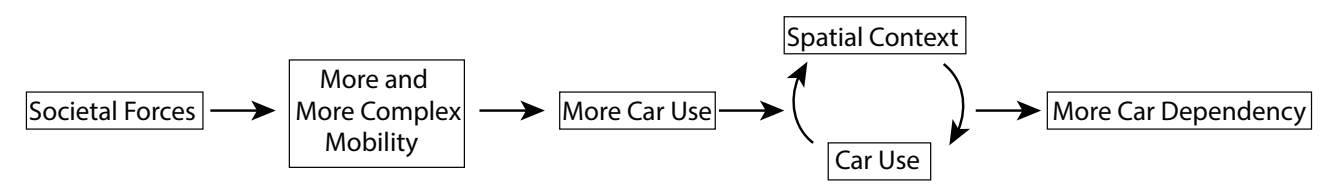

Figure 1: Driving forces behind car dependency

\subsection{Car dependency as a form of accessibility}

While Jeekel (2013) describes car dependency as a general societal development, Stradling's (2007) analyses of Scotland show differences between areas within a territory. In rural areas, people are sometimes totally dependent on their car while in urban areas people have more travel choices. Silva and Pinho (2010) also show that within a single urban area (Oporto), there might be big differences with regard to potential travel choices. They also make an important step in the conceptualization of the relationship between the spatial context and potential travel choice - they see travel choice and potential mobility as a feature of the combination of land use and transport features in an area, which together affect the accessibility of activities for those living there. Seen from this point of view, car dependency relates to the potential travel choices available within a given spatial context-i.e., accessibility.

According to Geurs and van Wee (2013) accessibility describes the extent to which land use and transport systems enable:

- Groups or individuals to reach activities or destinations by means of a combination of transport modes at various times of the day.

- Companies, public facilities, and other places of activity to receive people, goods, and information at various times of the day.

Accessibility does not describe actual travel behavior but rather the potential for travel behavior. van Wee and Geurs (2013) distinguish four components of accessibility: the land-use component (location of residential areas, centers of activities, etc.), the transport component (modes of transport), the temporal component (as in daily trips versus incidental trips), and the individual component (commuter, traveler for the purpose of a social visit, etc.).

Returning to our key question-How does the spatial context of cities and regions shape conditions for car dependency? - we find a gap in the existing literature. Several authors-for example, Newman and Kenworthy (1999), Kenworthy and Laube (1999), and Tayal et al. (2001) — describe the relation between the spatial context and car use, but not exclusively related to car dependency. Jeekel (2013) describes the general societal forces behind car dependency, with Handy (1993) adding a spatial dimension. Stradling (2007) shows how the spatial context of rural areas leads to the car dependency of the inhabitants of these areas. Silva and Pinho (2010) show the different accessibility levels and resulting travel choices within an urban region (Oporto). A systematic identification of the features of the spatial context that determine car dependency (i.e., specific land-use and transport components) is still lacking.

Using the four components of accessibility described by van Wee and Geurs (2013) and adopting a user point of view, the question of the relation between the spatial context and car dependency can be reframed as follows: How does the spatial context (i.e., the land-use and transport components of accessibility) shape conditions for the car dependency — the lack of alternative mode choices—of individuals in their daily trips to activities?

We will use this conceptualization for our operationalization of car dependency below. 


\section{$3 \quad$ Case and research methods}

\subsection{Case: the Netherlands}

To answer the question of how the spatial context of cities and regions shapes conditions for car dependency, we compare the spatial contexts of different areas to identify which transport and land-use components influence potential travel choices. Our field of study is the current situation in the Netherlands. Within the European context, the Netherlands is an interesting case for a number of reasons. First, it is relevant for other contexts because the scale and size of the city regions in the Netherlands are typical of many urbanized parts of Europe. Most people in the Netherlands live in medium-sized city regions ranging from 100,000 to 1 million inhabitants - which reflects the situation in most of Europe, where only a minority lives in larger metropolitan regions like Paris, London, or Berlin—or in rural towns and villages (Giffinger 2007). Second, most cities in the Netherlands are part of polycentric regions in which daily urban systems are interwoven, as is also the case in many urbanized zones in Europe, such as Northern England, parts of Germany, and Northern Italy. However, the Dutch situation is in another way atypical of the European context, most importantly because of the highly planned and compact character of the post-WWII residential extensions of cities, towns, and villages (Geurs and van Wee 2006) and relatively contained urban development patterns (Kenworthy and Laube 1999; Newman 1996). These characteristics are widely advocated in the literature and in policy debates as being important for reducing car dependency (Rogers 1997; Girardet 2004; Duany et al. 2000), making it interesting to assess in which measure and how this is the case.

\subsection{Measuring car dependency}

Car dependency is not an absolute concept, but it is related to the availability of alternative transport modes to an individual for making a trip. With respect to the spatial context, the land-use and transport components of accessibility can be seen as conditional for car dependency. However, as Geurs and van Wee (2013) point out, accessibility also has a temporal component (when is accessibility needed?). For this study, we distinguish three temporal levels of car dependency:

1. Never needing a car

2. Occasionally needing a car

3. Needing a car every day

Needing a car means that there is no reasonable alternative to the use of a car. Never needing a car is hypothetical for most people in the current situation in the Netherlands. Even people who can't drive or don't own a car need a car occasionally, albeit a taxi, ambulance, or the car of a family member. The second group — needing a car occasionally—is more substantial: the people in this group have access to a car but don't need it on a daily basis, just for incidental trips like some business or social visits, holidays, or a trip to large retail outlets such as furniture stores. In principle, they don't need to own a car and can rent one or share one when needed. People in the third group, however, need a car on a daily basis: they are, for instance, commuters who have no reasonable alternative for their trip to work or education. They have to own a car in most cases. The evidence shows that once they own a car and use it daily, these people tend to also use it for trips where a choice is possible (Van Acker 2010; Harms 2003). It follows, therefore, that there is an important threshold between levels two and tjree. In this study, the third group (needing a car every day) is the one considered to be car dependent. 


\subsection{Access to daily amenities and jobs}

When we view the transport needs of individuals in their daily activities, two main kinds of daily trips can be distinguished: trips from home to amenities like shops, health care, or primary schools, which are often local, and commuting trips to work or higher education, which are often more regional. They each set different conditions on the spatial context in relation to car dependency.

\subsubsection{Access to daily amenities}

For local trips to amenities, 1 kilometer can be seen as an important threshold, since it can be defined as the upper limit of an acceptable walking distance. It follows, then, that for trips of less than $1 \mathrm{~km}$, walking can be considered a reasonable alternative to the use of a car. Destinations within $2.5 \mathrm{~km}$ are considered to be an acceptable distance for cycling (Van de Coevering 2013), and for these trips the bicycle can therefore be considered a reasonable alternative to the use of the car. In this study, we have assumed that the aforementioned walking and biking distances are acceptable for everyone and do not further address the impact of variables such as age or the physical conditions of individuals. To identify these conditions, we have used data from Statistics Netherlands (CBS). These data give the average distance from homes to amenities within all the municipalities in the Netherlands, calculated by taking the average of the distance for all individuals who live in the municipality. Distances have been calculated over roads open for all traffic, not over footpaths or bike paths. Figure 2 summarizes this rationale.

Spatial context $\rightarrow$ Distances to amenities (acceptable walking and biking distances) $\rightarrow$ Car Dependency

Figure 2: Measuring car dependency in relation to the access of amenities

\subsubsection{Access to jobs}

In the Netherlands, people are prepared to commute to their jobs on average about 30 minutes each way, with a total daily commute of one hour (KIM 2010). Accordingly, to measure the level of car dependency in a given area with respect to access to jobs, we compared the number of jobs accessible by car, by bicycle, and by public transport (bus, tram, metro, and train) within a travel time of 30 minutes. This assessment of the travel choices to all jobs within 30 minutes in a given area is expressed as a travel choice score. When the number of jobs that can be reached within 30 minutes by public transport or bicycle equals that of the car, the travel choice score is set at 100 percent. When more jobs can be reached within 30 minutes by public transport or bicycle than by car, the travel choice score is proportionally more than 100 percent. When fewer jobs can be reached by public transport or bicycle than by car, the score is proportionally less than 100 percent. Travel choice score is an indicator of the level of car dependency in relation to access to jobs, as shown in Figure 3.

Spatial context $\longrightarrow$ Potential travel choices to jobs (Travel Choice Score) $\rightarrow$ Car Dependency

Figure 3: Measuring car dependency in relation to access to jobs.

Of course, it is possible that an individual who lives in an area where only a relatively limited number of jobs is accessible without a car within 30 minutes may still not use a car-if they can easily 
walk to their job, for instance. However, in this study we want to measure the potential travel choices from homes to jobs in a given area, not the actual travel choices for individuals. We follow the reasoning that -irrespective of the jobs residents in an area presently have-access to a diversity of jobs can be seen as a basic need and thus a requirement for selecting residential locations (e.g., considering the increasing job insecurity and job mobility in the current second phase of modernity). In this sense, someone who does not need a car to go to work today might need one in the future, and we want to assess in which measure this is the case.

To compare the different travel times per transport mode (car, bicycle, and public transport), we used the multimodal national transport model developed by Goudappel Coffeng (http://www.goudappel.nl/producten/websites/bereikbaarheidskaart). This transport model is based on a national database of the road network (NDW, http://www.ndw.nu), Open Street Map, and the existing timetables of public transport (http://ns24.nl/ov9292). Although this is a national model, the level of detail for both the car network (110,000 roads, streets, etc.) and the public transport network (4000 lines and 25,000 stops) can be considered sufficient for calculating travel times accurately on the regional level. Travel times by car were calculated for the morning peak period. Congestion is thus taken into account. Travel times for public transport include waiting time and time needed to travel to and from the station. The model has 6700 zones with 1 to 20,000 inhabitants per zone.

This accessibility analysis was carried out using a potential accessibility measurement with a distance decay or impedance function, with closer opportunities weighed more strongly than more distant ones. The travel time of 30 minutes indicates the turning point in our impedance functions, where a job is weighted precisely as one job. Jobs that can be reached within less than 30 minutes are weighted proportionally higher than one, and jobs that are further away than 30 minutes are weighted proportionally less than one.

\subsubsection{Land-use and transport characteristics}

Based on relevant land-use and transport components identified by the literature referenced in Section 2.3 (Newman and Kenworthy 1999; Kenworthy and Laube 1999; Tayal et al. 2001), we have considered the following characteristics of the spatial context:

- Degree of urbanization, as indicated by the density of addresses (http://www.CBS.nl, adressendichtheid, see Figure 4).

- Size of settlement: a "big city" has more than 500,000 inhabitants, a "medium-sized city" has between 100,000 and 500,000 inhabitants; and a "small city" has fewer than 100,000 inhabitants.

- Network of infrastructure: the road network, including bicycle and footpaths, and the public transport networks have been indirectly accounted for in travel time calculations. Furthermore, and as already mentioned, for the car the effect of congestion and for public transport the effect of actual schedules was considered. 


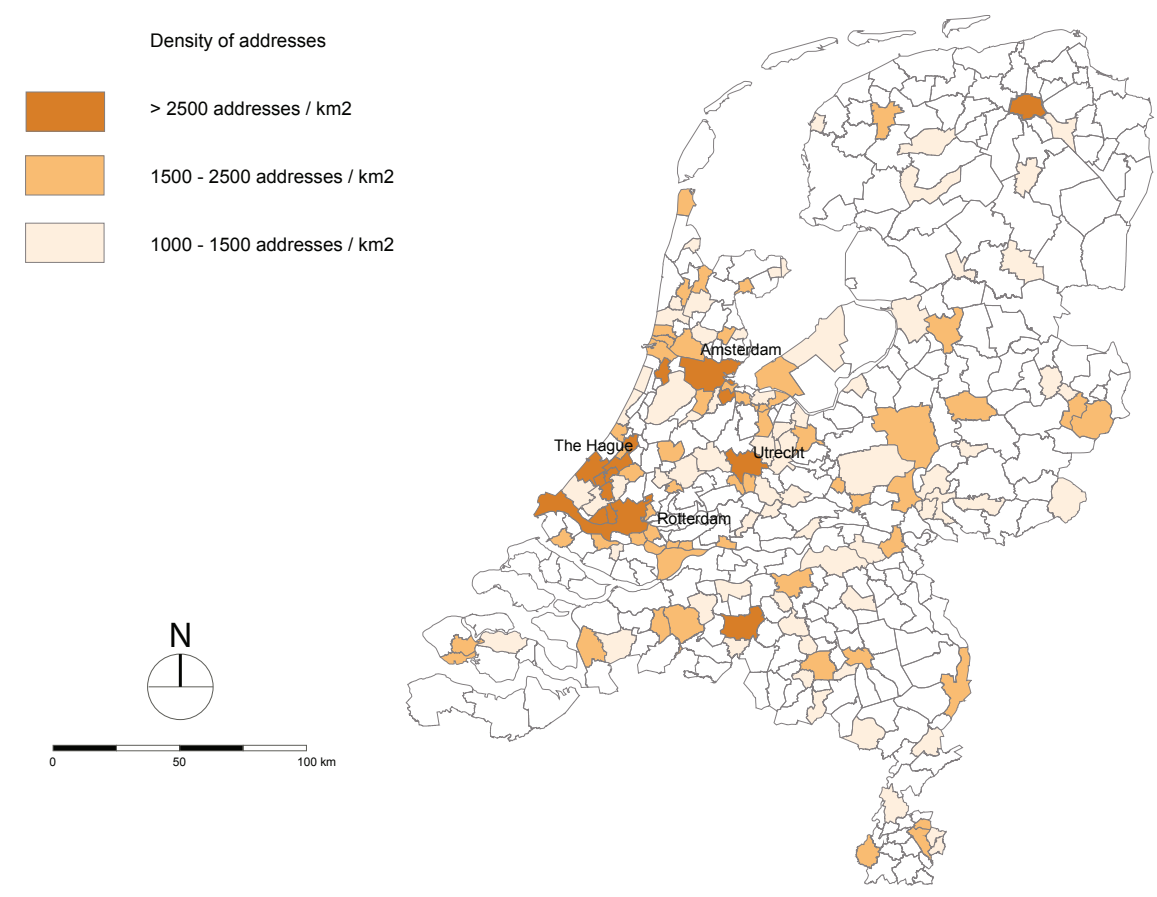

Figure 4: Density of addresses in the Netherlands. Source: http://www.cbs.nl, adressendichtheid

\subsubsection{Research sub-questions}

In conclusion, the distinction of two types of daily trips (to daily amenities and to jobs), of distance and travel time cut-off points, and of the above land-use and transport characteristics leads to three research sub-questions:

1. To what extent do distances from home to daily amenities exceed $1 \mathrm{~km}$ for walking and $2.5 \mathrm{~km}$ for cycling?

2. To what extent does the number of jobs accessible from residential areas within 30 minutes of travel time differ according to transport mode (bicycle, public transport, and car)?

3. What are the relationships between the findings from the previous two questions and the spatial context (degree of urbanization, size of settlement, network of infrastructure))?

\section{$4 \quad$ Research results}

\subsection{Accessibility of daily amenities}

In 2011, primary schools in almost all municipalities in the Netherlands were situated within walking distance -i.e., less than $1 \mathrm{~km}$ —of residential areas (http://www.cbs.nl, nabijheidsstatistiek; see Figure 5). There is no apparent relation to spatial context characteristics. Only in a few peripheral areas with low densities (and in certain new land extensions) does the average maximum distance rise towards $2.5 \mathrm{~km}$. This is not a comfortable walking distance. Due to population decline in some regions and the general aging of the population, areas in these latter conditions are expected to increase. In several regions of the Netherlands where the population is declining, the closure of up to 50 percent of the schools is being debated following a reduction in the numbers of children of school-going age, which will likely lead to 
an increase in average distances in many situations (G.S. Limburg 2013; Van Til 2007). Furthermore, it must be kept in mind that this is an average distance, meaning that within a municipality there could still be neighborhoods exceeding the threshold.

Distances to large supermarkets (with a minimum floor space of $150 \mathrm{~m}^{2}$, which guarantees a minimum of choice of products) show more variations between municipalities; furthermore, these variations correspond more with the density of addresses (http://www.cbs.nl/nabijheidsstatistiek; see Figure 6, compare Figure 4). Nevertheless, in urban and suburban areas, most people live within walking distance from a supermarket; in the more rural areas, a supermarket is mostly still within $2.5 \mathrm{~km}$, which can be considered biking distance. This is also true for medical centers (http://www.cbs.nl/nabijheidsstatistiek). As with primary schools, however, this might also change following population decline. In several regions of the Netherlands where population is declining, plans for merging medical centers and closing retail outlets are being discussed and sometimes have already been implemented. For instance, the number of shops in small villages (maximum 5000 inhabitants) in the province of Zuid Limburg has, since 2009, fallen by 11 percent (Graaf-Weerts de G. 2013).

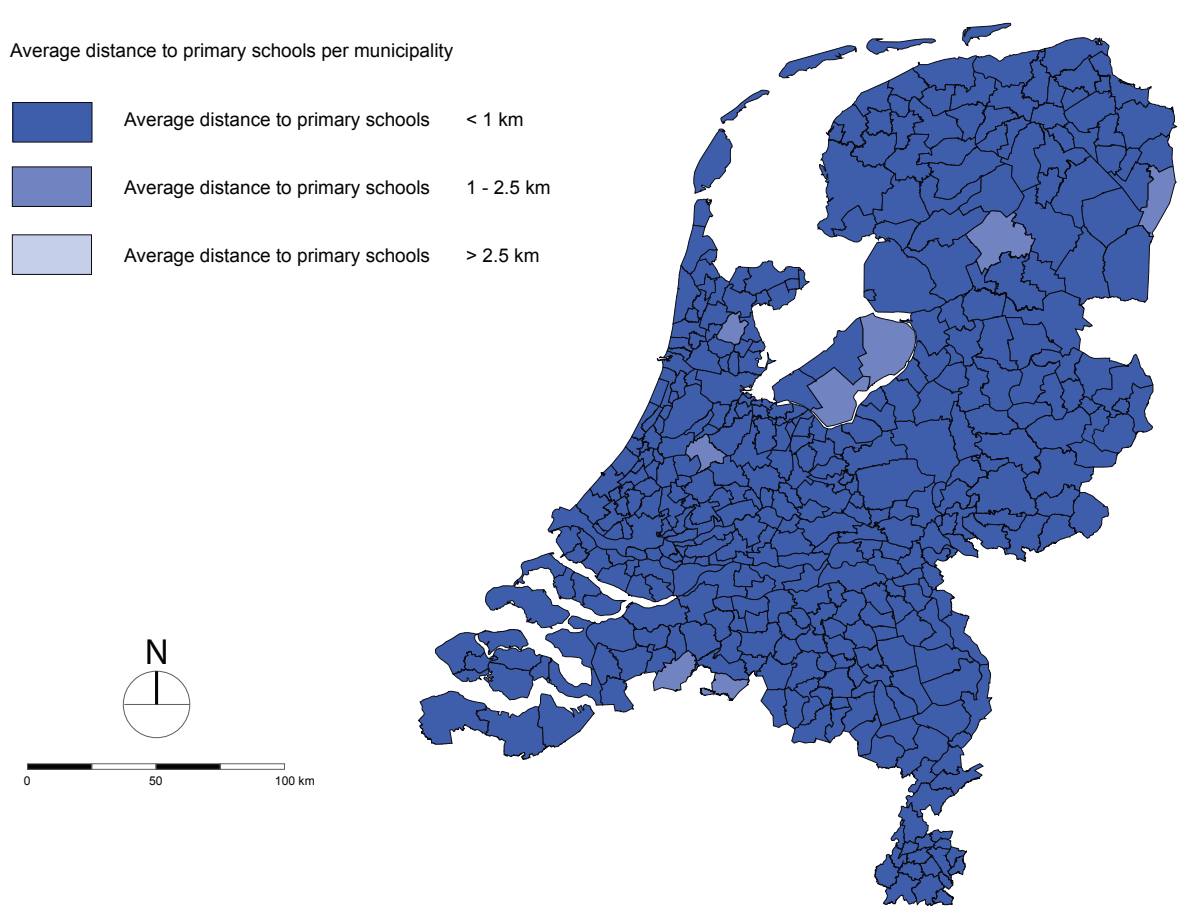

Figure 5: Average distance to primary schools per municipality (2011). Source: http://www.cbs.nl, nabijheidsstatistiek 


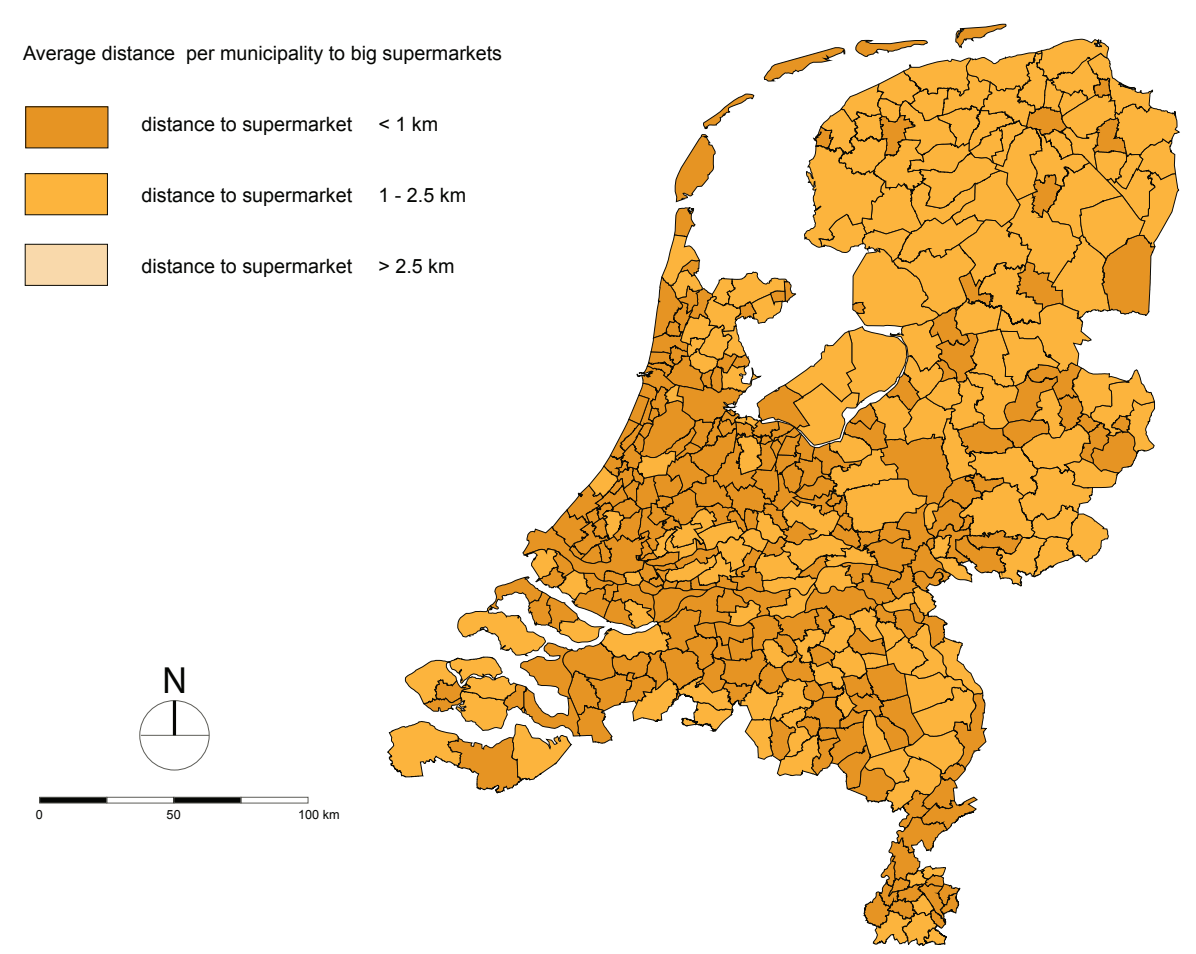

Figure 6: Average distance to large supermarkets (minimum floor space of $150 \mathrm{~m}^{2}$ ) per municipality (2011). Source: http:// www.cbs.nl, nabijheidsstatistiek

If we shift the metrics from average distances to the amounts of daily amenities within reach, we can see that the number of primary schools and large supermarkets within walking and cycling distance broadly corresponds with the density of addresses (see Figure 7 and 8 respectively, compare Figure 4). It is clear that in the big cities there is far greater choice of schools and large supermarkets within walking and cycling distance. This means that if the possibility to choose is factored in, car dependency grows exponentially in areas with a lower population density. 


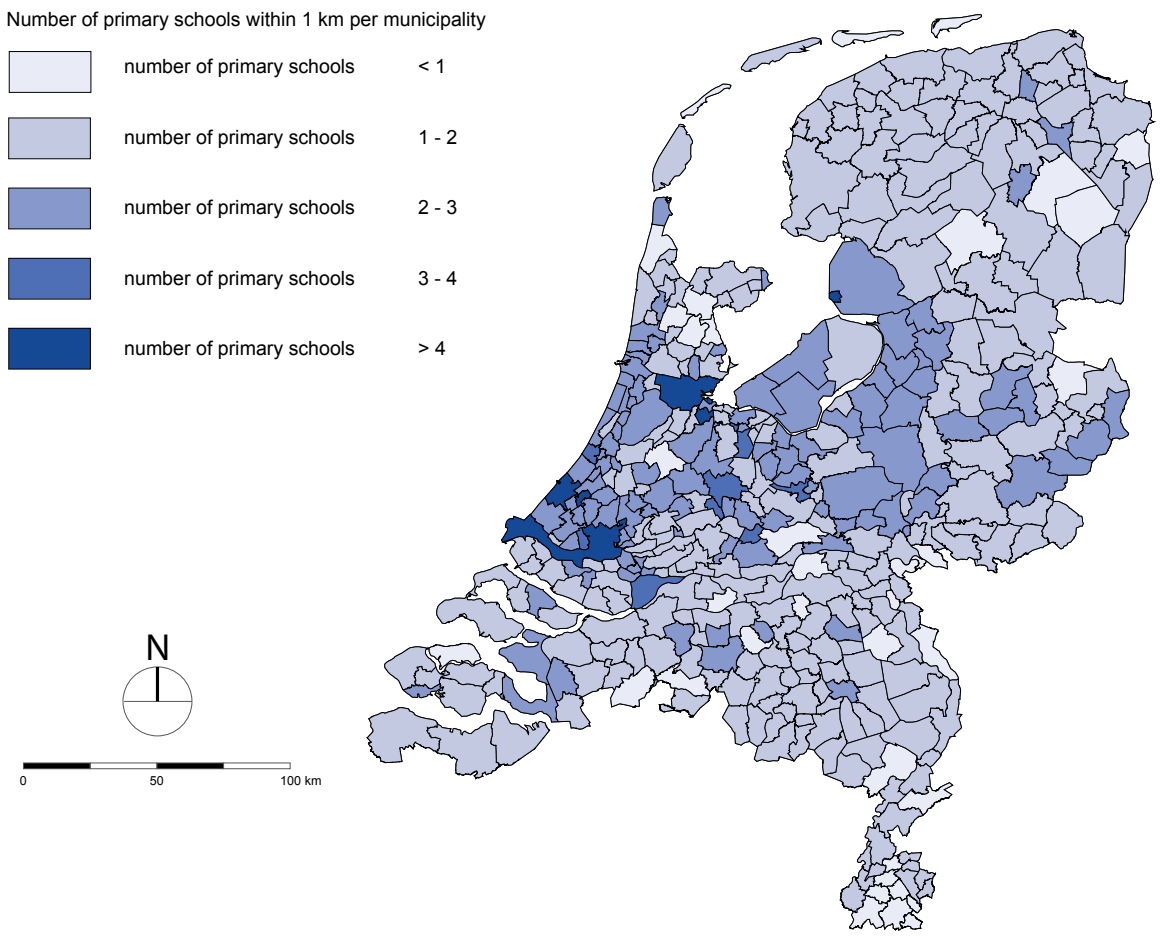

Figure 7: Number of primary schools within $1 \mathrm{~km}$ per municipality (2011). Source: http://www.cbs.nl, nabijheidsstatistiek

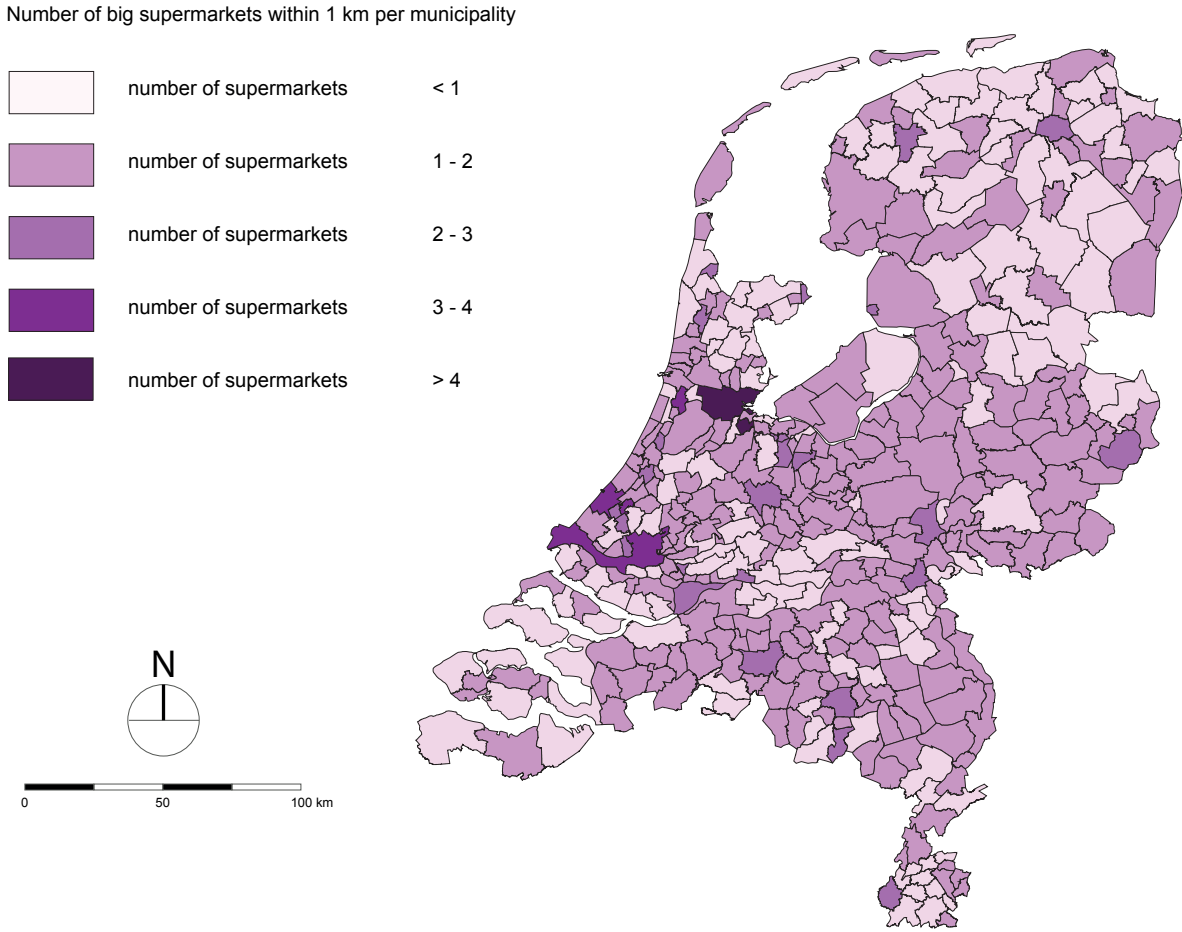

Figure 8: Number of large supermarkets (minimum floor space of $150 \mathrm{~m}^{2}$ ) within $1 \mathrm{~km}$ per municipality (2011) Source: http://www.cbs.nl, nabijheidsstatistiek 


\subsection{Accessibility of jobs}

In the Netherlands, people are prepared to travel to jobs for, on average, half an hour per trip, within a total daily travel time of about one hour (KIM 2010). To measure car dependency in relation to jobs, the number of jobs accessible by car within 30 minutes from a given area is compared with the number of jobs reachable by alternative modes within the same travel time. These alternative modes are public transport and bicycle. As discussed above, we use a travel choice score to determine the degree of car dependency for the accessibility of jobs. When the number of jobs that can be reached within 30 minutes by public transport or bicycle equals that of the car, the travel choice score is set at 100 percent. When there are more jobs that can be reached within 30 minutes by public transport or bicycle than by car, the score is proportionally more than 100 percent. When fewer jobs can be reached by public transport or bicycle, the score is proportionally less than 100 percent.

\subsubsection{Accessibility of jobs by bicycle compared with accessibility by car (within 30 minutes of travel time)}

Figure 9 shows that in areas with a degree of urbanization below 1500 addresses $/ \mathrm{km}^{2}$, cycling is not a competitive alternative to the car as a means of reaching jobs. Above 1500 addresses $/ \mathrm{km}^{2}$, the bicycle becomes a serious alternative in the central parts of some urbanized areas, with and average score of 20 to 40 percent. These scores are indicated in Figure 9 by a circle. The highest bicycle travel choice scores are found in the central areas of some medium-sized towns (100,000-500,000 inhabitants) in the periphery of the country. There, 40 to 60 percent of jobs are accessible within 30 minutes by bicycle, compared to those accessible by car. These scores are indicated in Figure 9 by a bullet. In the big cities (more than 500,000 inhabitants), only the central area of The Hague reaches a score of 40 to 60 percent. The other two big cities, Amsterdam and Rotterdam, have scores of 20 to 40 percent in their central areas.

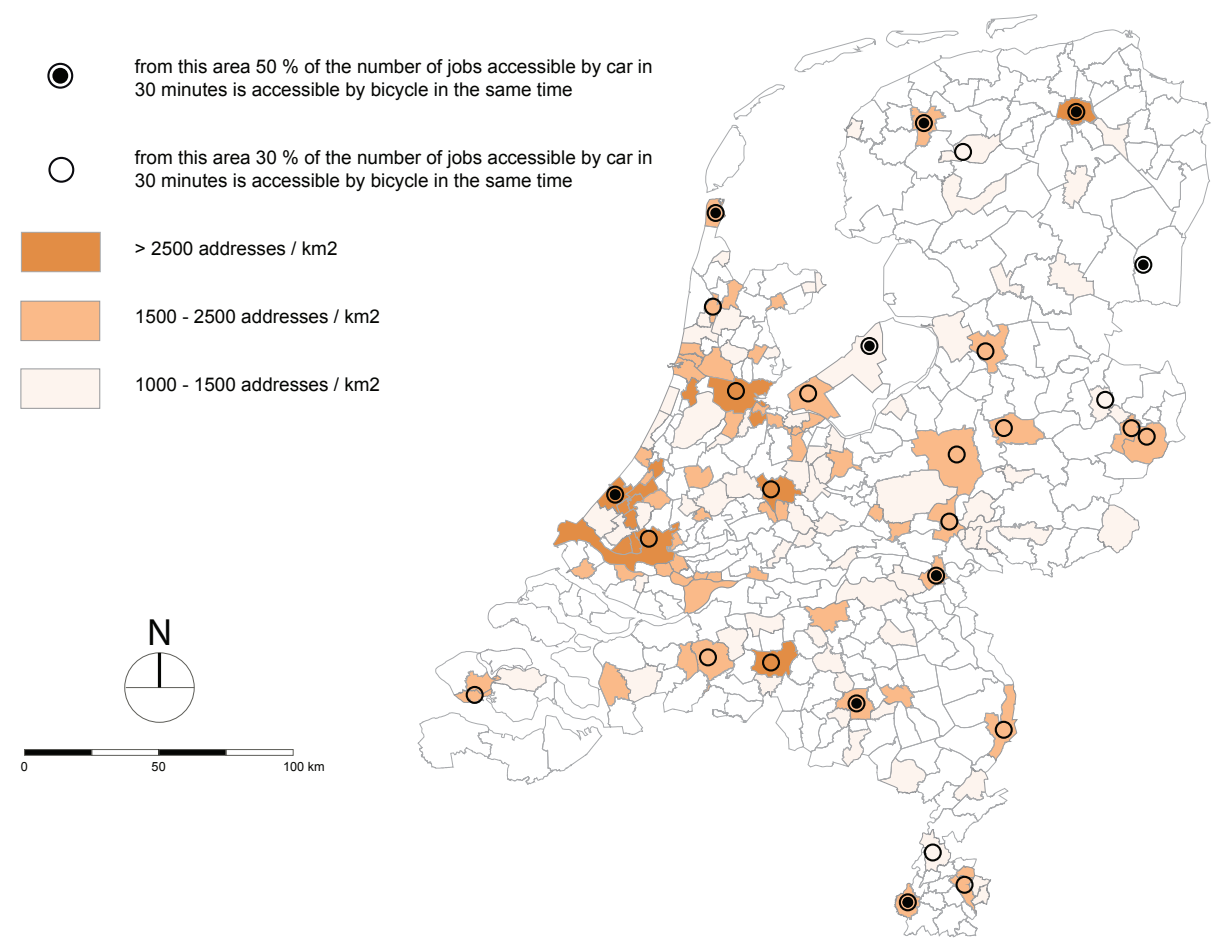

Figure 9: Number of jobs accessible by bicycle in 30 minutes, compared to car 


\subsubsection{The accessibility of jobs by bicycle: Relationship with the spatial context}

Apparently high urbanization—density of above 1500 addresses $/ \mathrm{km}^{2}$ or city size above 100,000 inhabitants - is not sufficient for explaining the differences in travel choice score for the bicycle. Commuting by bicycle scores highest in medium-sized cities that are surrounded by a low-density rural area, which points to the effect of regional jobs being concentrated in one center or the city having a "hard" geographical border such as a coast, a national border, or a natural area (i.e., a de facto concentration effect). In order to more systematically explore these findings, in Table 1 we introduced monocentricity and polycentricity as further features of the spatial context. Table 1 documents a clear pattern of a stronger competitive position of the bicycle in monocentric areas. In a monocentric urban region, jobs are concentrated in one center. A polycentric region is composed of several centers and no single center is dominant in terms of jobs (Grünfeld 2010). This absence of a single regional focus for commuting trips might explain why in polycentric regions like the Randstad, the bicycle as an alternative transport mode to jobs does not score higher than 20 to 40 percent. An exception seems to be the central area of The Hague, a big city that is part of a polycentric region of the Randstad. But this, as already mentioned, can be explained by the effect of the coast, a "hard" geographical limit to the spatial dispersion of jobs - and thus amounts to further evidence of the positive effect of employment concentration on bicycle competitiveness.

Table 1: Accessibility of jobs by bicycle (30 minutes), compared to accessibility by car (30 minutes), related to city size and type of spatial structure

\begin{tabular}{|l|l|l|}
\hline & Polycentric region & Monocentric region \\
\hline City over 500,000 & $\begin{array}{l}20-40 \% \text { in central area } \\
\text { (except in border or coastal situation, where } \\
\text { it is around 50\%) }\end{array}$ & $*$ \\
\hline City 100,000-500,000 & $20-40 \%$ in central area & $40-60 \%$ in central area \\
\hline Small town/ suburban area & Under $20 \%$ & Under 20\% \\
\hline Rural area & Under $20 \%$ & Under 20\% \\
\hline
\end{tabular}

* No cities of this description exist in the Netherlands

4.2.3 Accessibility of jobs by public transport compared with accessibility by car (within 30 minutes travel time)

Figure 10 shows that in areas with a degree of urbanization below 1500 addresses $/ \mathrm{km}^{2}$, public transport is in no case a competitive alternative to the car as a means to reach jobs within 30 minutes of travel time. Above 1500 addresses $/ \mathrm{km} 2$, public transport becomes a serious alternative in the central parts of some urbanized areas, with average scores of 20 to 40 percent. These scores are shown in Figure 10 by a circle. The highest travel choice scores in relation to public transport are found in the central areas of some medium-sized towns where 40 to 60 percent of jobs are accessible within 30 minutes by public transport, compared to those accessible by car. These scores are shown in Figure 7 by a bullet.

\subsubsection{The accessibility of jobs by public transport in $\mathbf{3 0}$ minutes: Relationship to the spatial context}

Apparently high urbanization — density of above 1500 addresses $/ \mathrm{km} 2$ or city size above 100,000 inhabitants-is not sufficient for explaining the differences in travel choice scores for public transport within 30 minutes. The highest travel choice scores are around the railway station areas of medium-sized 
cities in monocentric or border regions, where the bicycle also has a strong position. Here, a similar reasoning to that made for the bicycle above seems to apply. But there are some polycentric regions where public transport can reach more jobs than the bicycle within 30 minutes (e.g., Almere, a city close to Amsterdam, and the Twente region with two towns within short distance from each other). Apparently the proximity of another center with a concentration of jobs can give public transport a strong position. Utrecht, a major public transport node in the Netherlands, is another such example.

Table 2: Accessibility of jobs by public transport (30 minutes), compared to accessibility by car (30 minutes), related to city size and type of spatial structure

\begin{tabular}{|l|l|l|}
\hline & Polycentric region & Monocentric region \\
\hline City over 500,000 & $\begin{array}{l}20-40 \% \text { in central area } \\
\text { (except in border situations, } \\
\text { where it is around 50\%) }\end{array}$ & $*$ \\
\hline City 100,000-500,000 & $\begin{array}{l}20-40 \% \text { in central area in } \\
\text { most cases }\end{array}$ & $40-60 \%$ in central area \\
\hline Small town/ suburban area & Under 20\% & Under 20\% \\
\hline Rural area & Under 20\% & Under 20\% \\
\hline
\end{tabular}

* No cities of this description exist in the Netherlands

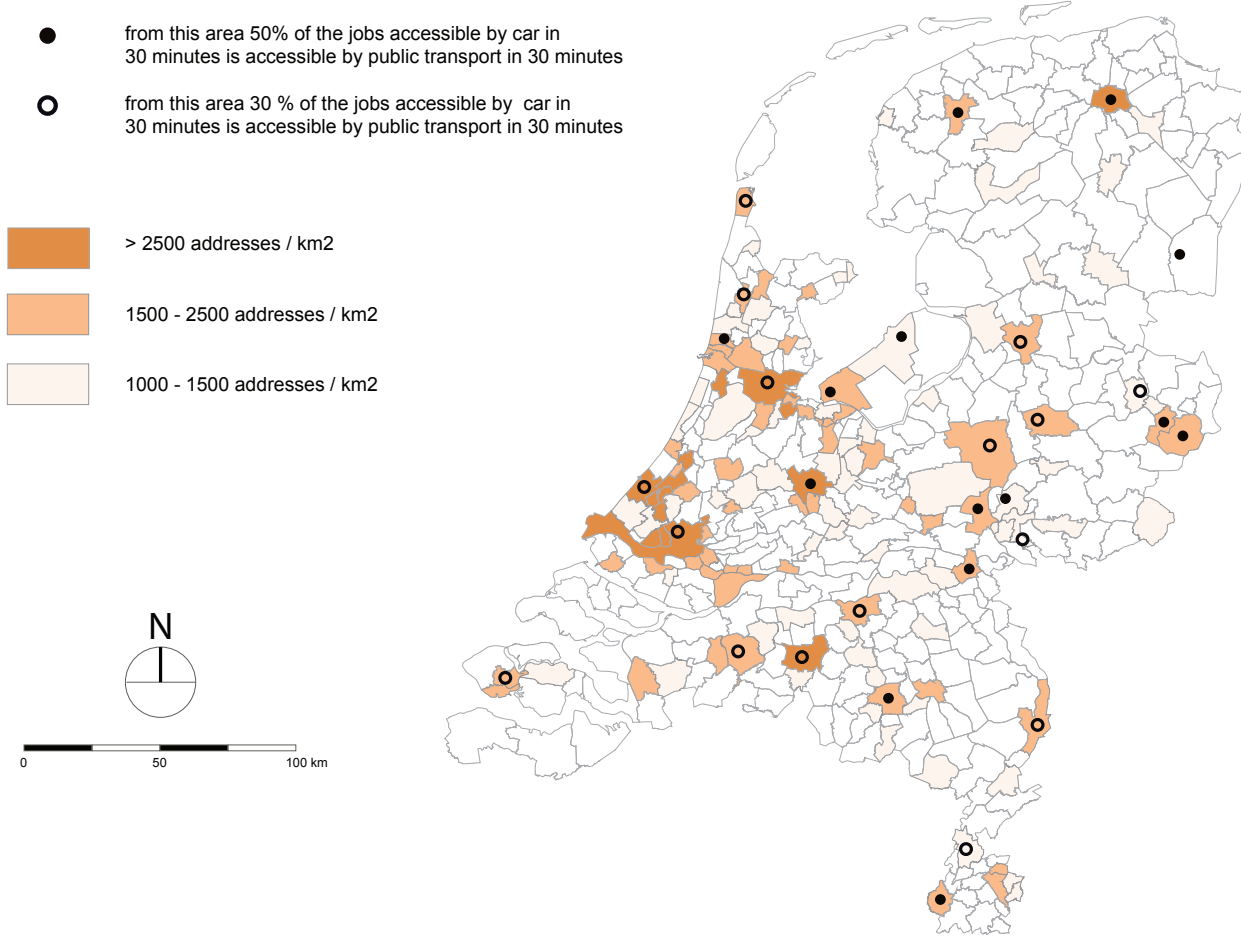

Figure 10: Number of jobs accessible by public transport within 30 minutes of travel time, compared to car

4.2.4 Accessibility of jobs by public transport (45 minutes of travel time), compared with accessibility by car (30 minutes of travel time) 
If the benchmark of travel time for public transport is raised to 45 minutes compared to 30 minutes by car-based on the observation that in the Netherlands people on average commute about 30 minutes by car but about 45 minutes when using public transport (www.CBS.nl)—we would have more locations with relatively high travel choice scores (see Figure 11). There are even places where more jobs are found within 45 minutes by public transport than within 30 minutes by car (shown by bullets in Figure 11). These places are found in central areas of medium-sized cities, some small towns, and suburban areas. The central areas of big cities of Amsterdam, Rotterdam, and The Hague (over 500,000) have a relatively low travel choice score compared to most medium-sized cities. In most cases, the travel choice score in central areas of these big cities reaches around 80 percent (shown by circles in Figure 11). Only in the areas directly adjoining the main intercity train stations is the score more than 100 percent (not shown in Figure 11).

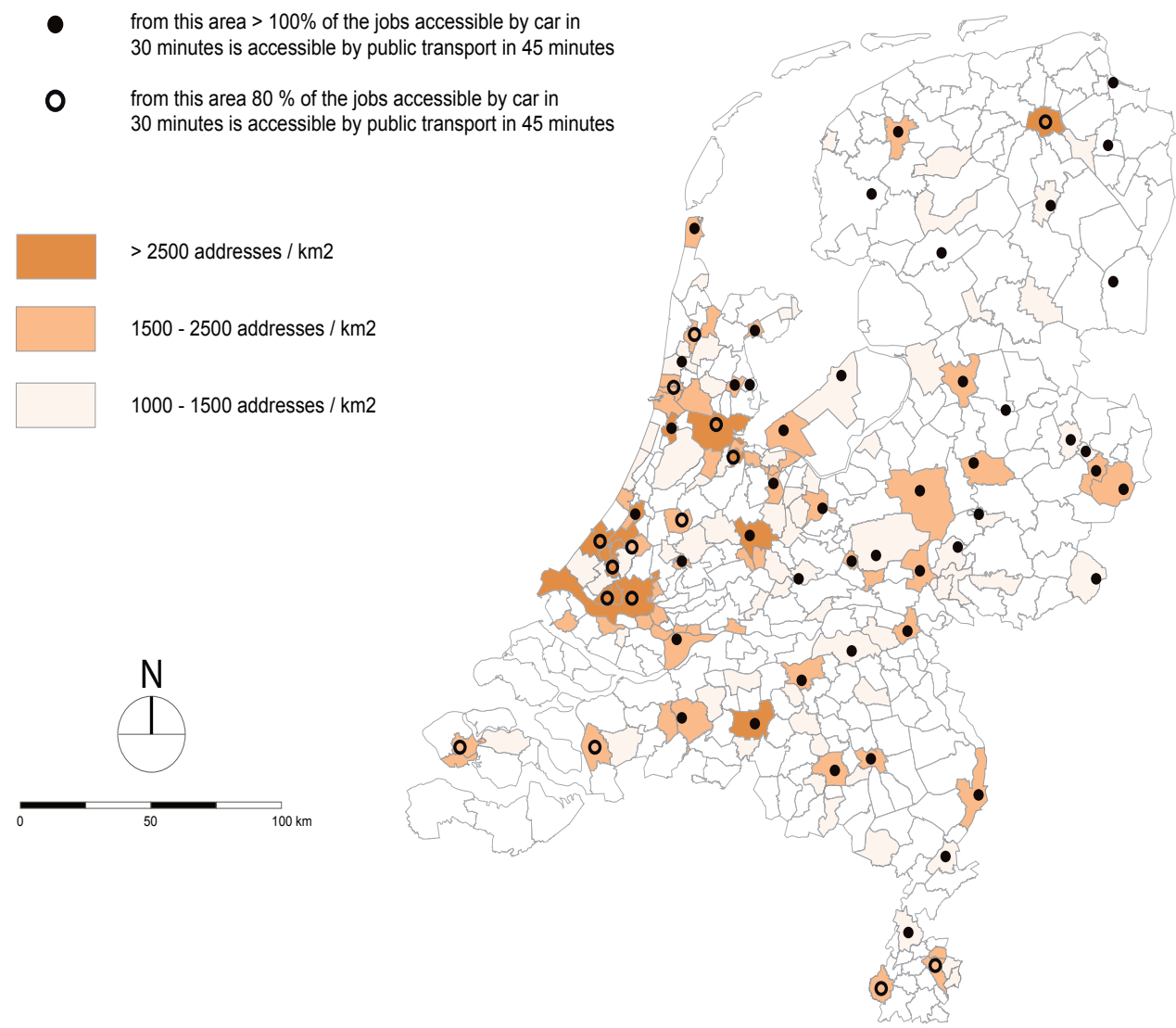

Figure 11: Number of jobs accessible by public transport within 45 minutes, compared to car within 30 minutes

4.2.5 The accessibility of jobs by public transport within 45 minutes: Relationship to the spatial structure

The overall picture is intriguing and, at first impression, counterintuitive. As shown in Table 3, the highest travel choice scores related to public transport within 45 minutes are in the central areas of mediumsized cities, some small cities, and suburban areas. In the central areas of big cities within the dense urban field of the Randstad, the most heavily urbanized part of the Netherlands, scores are lower. By contrast, small towns and suburban areas near railway stations in the surrounding areas of these big cities score very high. The findings could be explained by road traffic congestion traveling toward the city centers, which have strong concentrations of jobs, combined with the relatively high quality of public transport 
services to those jobs, together leading to higher public transport travel choice scores in outlying suburbs and small towns. Conversely, urban residents who commute to suburban job locations face little traffic congestion, which, combined with the relatively low quality of public transport services to those jobs, results in lower public transport travel choice scores for central urban areas.

Table 3: Accessibility of jobs by public transport (within 45 minutes), compared to accessibility by car (within 30 minutes), related to city size

\begin{tabular}{|l|l|}
\hline City over 500,000 & $80 \%$ in central area \\
\hline City $100,000-500000$ & Over $100 \%$ in central areas \\
\hline Small town, suburban area & Over $100 \%$ in central areas \\
\hline Rural area & Under $20 \%$ \\
\hline
\end{tabular}

\subsection{Travel choice scores of the national population in relation to job access}

To allow for an overall assessment, Table 4 shows the travel choice scores (or degree of car independency) of the national population in relation to job access.

Table 4: Travel choice scores of the national population in relation to job access

\begin{tabular}{|l|l|l|l|l|l|}
\hline & \multicolumn{5}{|c|}{ Travel choice score } \\
\cline { 2 - 6 } & $0-20 \%$ & $20-40 \%$ & $40-60 \%$ & $60-80 \%$ & Over 80\% \\
\hline $\begin{array}{l}\text { \% population } \\
\text { Bicycle 30min./Car 30 min. }\end{array}$ & $73.6 \%$ & $22.7 \%$ & $3.7 \%$ & $0.1 \%$ & $0.0 \%$ \\
\hline $\begin{array}{l}\text { \% population } \\
\text { Public Transport 30min./Car 30 } \\
\text { min. }\end{array}$ & $76.3 \%$ & $21.3 \%$ & $2.3 \%$ & $0.0 \%$ & $0.0 \%$ \\
\hline $\begin{array}{l}\text { \% population } \\
\text { Public Transport 45 min./Car 30 } \\
\text { min. }\end{array}$ & $11.1 \%$ & $24.3 \%$ & $25.4 \%$ & $19.5 \%$ & $19.7 \%$ \\
\hline
\end{tabular}

In Table 4, we combined the travel choice scores with population densities derived from CBS data. As Table 4 illustrates, very few people live in areas where cycling or public transport seriously competes with the car in the accessibility of jobs. Less than 4 percent of the Dutch population lives in an area where at least 40 percent of the jobs accessible by car within 30 minutes are also accessible by bicycle in the same travel time - and less than 3 percent if public transport is considered. Only when the journey time by public transport is increased to 1.5 times the travel time by car is public transport an attractive alternative. Even in this case, only about 20 percent of the population lives in areas where public transport is a strong alternative to the car (80 percent or more).

\section{Conclusions, discussion, and further research}

\subsection{Conclusions}

Almost all people in the Netherlands live in places where daily amenities like primary schools, large supermarkets, and medical centers are within walking distance, regardless of density or city size. However, the possibility of choice between amenities is positively influenced by density and city size. This result 
has strongly been influenced by policy over recent decades. Concentration of homes within or adjoining existing centers has long been promoted, as well as an ubiquitous availability of primary schools. Furthermore, since the 1960s the Dutch national government outright banned the development of large shopping malls outside the existing urban centers. Another relevant point is that, in comparison to many other countries, the Netherlands has no truly remote, sparsely populated areas, due to its high average population density and its diffuse urbanization patterns. However, this may change in the future, particularly in rural areas in the periphery of the country, as declining populations force both public and private providers to consider a drastic reduction in the number of facilities. It is also worth remembering that the possibility of a choice between daily amenities within walking or cycling distance is much higher in the more densely populated areas.

With regards to the accessibility of jobs, the car is the most competitive transport mode within 30 minutes of travel time in all spatial contexts. Our analysis shows that the transport and land-use characteristics of the spatial context of the Netherlands significantly limit travel choice for daily commuting, even in the most urban areas.

Looking beyond these general patterns, we made a number of observations on how the spatial context shapes conditions for car dependency in relation to the accessibility of jobs.

- Density (degree of urbanization, expressed by density of addresses) is an explaining factor for car dependency only up to a concentration of 1500 addresses $/ \mathrm{km}^{2}$. Above this density, there is no apparent relation to the competitiveness of any alternative transport modes.

- Size of settlement (city size): Cities with over 100,000 inhabitants show favorable conditions for bicycle and public transport within 30 minutes of travel time. However, when the benchmark of 30 minutes of travel time for public transport is raised to 45 minutes, city size does matter, but in a negative way: Big cities have lower scores than medium-sized cities and some large suburban areas.

- Network of infrastructure (the road network, including bicycle and footpaths, and public transport networks): Station areas (intercity and suburban) and their surroundings have relatively high travel choice scores, especially up to 45 minutes. Conversely, road congestion (mostly around the big cities) seems to explain the competitiveness of public transport with 45 minutes of travel time.

- Monocentricity/Polycentricity: Our research showed that this is an important feature of the spatial context in relation to car dependency. Monocentricity favors bicycle and local public transport up to 30 minutes of travel time. When the travel time is raised to 45 minutes, polycentrism seems to become an advantage for public transport, but this effect seems to be strongest in the central areas of medium-sized cities and suburban areas, not in the central areas of big cities. A likely explanation is the asymmetric quality of transportation networks, with public transport relatively more competitive when commuting from the suburbs to the cores and relatively less competitive when commuting from the cores to the suburbs.

Central areas of cities offer more travel choices to daily amenities and jobs than most suburban and rural areas. This finding follows the results of other studies and is even considered to be common knowledge. But our research revealed surprising differences between central urban areas in other respects. Although the absolute accessibility of jobs by all modes scores high in central areas of big cities, the relative accessibility of jobs by bicycle and particularly public transport from these areas seems to be lower than from central areas in some medium-sized cities and large suburban areas. We will return to this in Section 5.3.

\subsection{Limitations}

There are several limitations to our study. We analyzed the accessibility of jobs in general. It could be 
argued that variety in daily travel choices for commuting is correlated with higher education. White collar professionals are prepared to travel longer distances to their jobs and perhaps some of them are more inclined to select alternative transport modes, due to particular lifestyle preferences (Kuhnimhof 2011; Florida 2010). Furthermore, from the spatial perspective, it can be assumed that knowledge jobs are more frequently situated in central areas of cities than, for instance, industrial jobs. Somewhat lower car dependency scores might thus be expected. By contrast, in places like the industrial area of Rotterdam, which has low travel choice scores in relation to both bicycle and public transport, the resulting car dependency is worrying. The residents of these areas tend to have lower education levels and are also socially more vulnerable; as a result, they generally tend to have less access to cars. Further exploration of all these aspects is needed.

We did not include higher education institutions as a destination in our research. Journeys to campus by students can be seen as part of the regional commuting pattern and are in this sense relevant to the relationship between the spatial context and car dependency. However, as most students (certainly university students) in the Netherlands live in the place where they study, the bicycle is for them often a viable alternative, which also could partly explain the high and growing bicycle use in university cities like Amsterdam or Groningen. Further research could shed more light in this area.

For children, the daily trip to school is an important part of their mobility pattern. However, children today are more tied to time schedules caused by activities outside school, like extra-curricular courses, sports, and recreation. In our research, we did not count these activities as daily, but of course for parents, certainly those with more than one child, the commute to and from these activities could easily become a daily pattern, in some cases leading to car dependency. More exploration of this dimension is necessary.

The electric bicycle enjoys a growing popularity in the Netherlands (KIM 2014) and can cover greater distances than the traditional bicycle. We did not explore the possibilities of the electric bicycle as an alternative transport mode to amenities and jobs. However, especially in monocentric regions or cities with a border position, the possibilities of the electric bicycle look promising and need specific consideration. Furthermore, in the Netherlands as much as half of those taking a train access the station by bicycle (KIM 2014), suggesting that the bicycle-train combination should also be explored as an alternative transportation mode with specific possibilities (faster than the bicycle, more flexible than public transport).

A more general and fundamental issue is that, in the case of accessibility of jobs, we looked at relative degrees of car dependency instead of setting an absolute threshold. Based on the collected data, it was not possible to set such a threshold. In other words, we could not answer the following questions: Which travel choice scores (percentage of jobs accessible by other means, relative to the car) shape the conditions for car independency? Is it 100 percent, or could it also be less? And how is this related to the absolute number of accessible jobs? Furthermore, our analysis is aggregated, meaning that we cannot say whether a general statement also applies to an individual case. We assumed that access to a wide diversity of jobs (approximated by their total number) is a key and valued feature of a residential location and one that is becoming more important due to increasing flexibility and variability in private life and employment arrangements (as discussed in Section 2.2).

\subsection{Reflections and further research}

The observation in Section 5.1 (fewer travel choices to jobs in big cities compared to medium-sized cities) fails to correspond with observed travel behavior. For instance, in Amsterdam, the use of bicycles and especially public transport is relatively high compared to other cities and is still growing, at the cost of car use. Car ownership is also remarkably lower in the big cities than in medium-sized cities (Stienstra 
2008). One possible explanation could be that because in absolute rather than relative terms, more jobs can be reached from central areas of big cities like Amsterdam than from medium-sized cities; in actual terms, there are enough jobs available to choose from. A counterargument, however, would state that in big cities there is also more competition for jobs (there are more workers), which would balance out the increased job offer. A second possible explanation could be that the heavy use of alternative transport modes in Amsterdam and other big cities has more to do with the proximity of a rich variety of amenities and less with the accessibility of jobs. This situation would also produce second order effects: because one does not need a car for daily amenities, there are fewer incentives to buy a car and more reasons to seek alternative travel options for commuting. Research on the purpose, length, and destination of trips made by different modes can help shed light on this topic. A third and more fundamental possible explanation could be that spatial conditions cannot predict travel behavior without additional information. Two classes of additional factors need to be accounted for. First are other factors that affect spatial conditions but were not included in the analysis - for example, the availability and cost of parking or the frequency of public transport services, which varies greatly between larger and smaller cities. Second and most importantly, in our study we did not account for socioeconomic, demographic, or cultural characteristics of the populations, which are crucial mediating factors between the characteristics of the built environment and travel behavior (Van Acker et al. 2010). A related open issue is self-selection (Bagley and Mokhtarian 2010; Maat 2012; van Wee 2009): Do car (in)dependent people and/or jobs self-select themselves into certain areas? Further research would be needed in order to disentangle the impact of different factors on actual travel choices. In closing, we would like to recall, however, that this is not the focus of our study, which examined the potential for travel choices-a necessary but not a sufficient driver behind actual travel choices.

\subsection{Policy implications}

Our study confirms that the competitiveness of alternative transport modes is heavily dependent on the spatial context. While this phenomenon needs to be researched in more detail, some implications for policy development can be distilled. In monocentric regions, improving cycling conditions could be the most effective answer to car dependency in relation to jobs. In polycentric regions, policies that favor the location of jobs and services in city centers and near railway stations and the improvement of the system of regional public transport seem to be the most effective measures.

Furthermore, although it is unlikely that the spatial context will fundamentally change in the Netherlands, societal trends may still have significant impacts, and adequate policies could provide much needed guidance. For instance, there is some indication that some offices are turning away from highway locations in favor of the city center and railway station areas, which could reduce car dependency. Policies could support and reinforce this. Also, the advent of high speed rail (HSR) and growth in air travel could influence regional spatial structures. Improving public transport connections with HSR stations and airports could give a boost to regional public transport as a structuring element in spatial developments and reduce the level of car dependency in the region.

Some trends, however, point in the opposite direction. Depopulating and aging regions in the Netherlands are experiencing a simultaneous reduction in the number of facilities and a concentration

of the remaining facilities in specific locations. Regrettably, recent decisions indicate a preference for siting these new regional hospitals, retail outlets, and higher education facilities in very car-dependent locations in peripheral areas, such as alongside highways. Awareness of the accessibility implications of these location choices could help identify policy measures that address this problem. For example, policymakers in these regions could reduce the level of car dependency by siting new regional facilities at railway stations or within existing centers. 


\section{References}

Bagley, M. and P. Mokhtarian. 2001. The impact of residential neighbourhood type on travel behaviour: A structural equations modeling approach. The Annals of Regional Science 36: 279-297.

Brindle, R. 2003. Kicking the habit: some musings over the meaning of car dependence. Road and Transport Research 12(3): 61-73.

Beck, U. 1992. Risk Society: Towards a New Modernity. Nottingham, UK: Sage Publications

Centraal Bureau voor de Statistiek. http://www.cbs.nl/nabijheidsstatistiek (accessed June 2013)

- http://www.cbs.nl/adressendichtheid (accessed June 2013)

Cheng, J. and L. Bertolini. 2013. Measuring urban job accessibility with distance decay, competition and diversity. Journal of Transport Geography 30: 100-109.

Dennis, K. and J. Urry. 2009. After the Car. Cambridge: Polity.

Duany, A., E. Plater-Zyberk, and J. Speck. 2000. Suburban Nation. New York: North Point Press.

Geurs, K. and B. van Wee. 2006. Ex-post evaluation of thirty years of compact urban development in the Netherlands. Urban Studies 43(1): 139-160.

Geurs, K. and B. van Wee. 2013. Accessibility: Perspectives, measures and application. In The Transport System and Transport Policy. Cheltenham: Edward Elgar Publishers, 207-226.

Florida, R. 2010. The Great Reset. New York: Harper.

Gedeputeerde Staten Limburg (2013). Voor de kwaliteit van Limburg, Concept POL 2014. Maastricht: Provincie Limburg.

Giffinger, R. and E. Meyers. 2007. City Ranking of European Mid-sized Cities. Vienna: Vienna University of Technology.

Girardet, H. 2004. Cities People Planet. Chichester: Wiley Academy.

Givoni, M. 2006. Development and impact of the modern high speed-train: a review. Transport Reviews 26(5): 593-611.

Gorham, R. 2002. Car dependence as a social problem: A critical essay on the existing literature and future needs. In Social Change and Sustainable Transport. Bloomington: Indiana University Press, $107-115$.

Goudappel Coffeng. http://www.goudappel.nl/producten/websites/bereikbaarheidskaart.(accessed June 2013)

Goudappel Coffeng. 2009. Ik fiets en ik vlieg. Deventer: Goudappel Coffeng.

Graaf-Weerts de, G. 2013. Dorpswinkel nog zeldzamer. Dagblad de Limburger.

Grünfeld, J. 2010. De polycentrische stedeling centraal: een onderzoek naar het veranderende palet van plekken in een polycentrische stedelijke regio. http://dare.uva.nl/record/339509 (accessed May 2014).

Handy, S. 1993. A cycle of dependence: automobiles, accessibility, and the evolution of the transportation and retail hierarchies. Berkeley Journal 8: 21-43.

Harms, L. 2008. Overwegend onderweg. De leefsituatie en de mobiliteit van Nederlanders. Den Haag: Sociaal Cultureel Planbureau.

Harms, S. 2003. From routine choice to rational decision making between mobility alternatives. Conference paper STRC 2003, Swiss Transport Research Conference.

Hilbers, H., P. Van de Coevering, and A. Van Hoorn. 2009. Openbaar vervoer, ruimtelijke structuur en flankerend beleid: de effecten van beleidsstrategiën. Den Haag/Bilthoven: Planbureau voor de Leefomgeving.

Jeekel, H. 2013. The Car-dependent Society. Farnham: Ashgate Publishing Group.

Kaufmann, V., M. Bergman, and D. Joye. 2004. Motility: Mobility as capital. International Journal of 
Urban and Regional Research 28: 745-756.

Kennisinstituut voor Mobiliteitsbeldeid KiM. 2010. Mobiliteitsbalans 2010. Den Haag: Ministerie van Infrastructuur en Milieu.

Kennisinstituut voor Mobiliteitsbeldeid KiM. 2014. Mobiliteitsbalans 2014. Den Haag: Ministerie van Infrastructuur en Milieu.

Kenworthy, J. R. and F. B. Laube. 1999. Patterns of automobile dependence in cities: an international overview of key physical and economic dimensions with some implications for urban policy. Transportation Research Part A 33: 691-723.

Kuhnimhof, T., R. Buechle, and J. Dargay. 2011. A new generation travel trends among young Germans and Britons. Transportation Research Record 2230: 58-67.

Litman, T. and F. Laube. 2002. Automobile Dependency and Economic Development. Victoria, Canada: VTPI.

Litman, T. 2002. The Costs of Automobile Dependency and the Benefits of Balanced Transportation. Victoria Canada: Transport Policy Institute.

Litman, T. and R. Steele. 2011. Land Use Impacts on Transport. Victoria, Canada: VTPI.

Millard-Ball, A. and L. Schipper. 2011. Are we reaching peak travel? Transport Reviews 31(3): 357-378.

Maat, K. 2012. Slimme verstedelijking zorgt voor complex mobiliteitsgedrag. Milieu Dossier September 2012, Utrecht: VVM.

Marlet, G. 2009. De aantrekkelijke stad. Nijmegen: VOC Uitgevers.

Newman, P. 1996. Reducing automobile dependence. Environment and Urbanization 8(1).

Newman, P. and J. Kenworthy. 1999. Sustainability and Cities: Overcoming Automobile Dependency. Washington, DC: Island Press.

Rogers, R. 1997. Cities for a Small Planet. London: Faber \& Faber.

Sennett, R. 2006. The Culture of the New Capitalism. London: Yale University Press.

Sheller, M. and J. Urry. 2006. The new mobilities paradigm. Environment and Planning A 38: 207-226.

Steer Davis Gleave. 2005. Overcoming Car Dependence. London: Transport for London.

Silva, C. and P. Pinho. 2010. The Structural Accessibility Layer (SAL): revealing how urban structure constrains travel choice. Environment and Planning A 42: 2735-2752.

Stienstra, S. 2008. Parkeerbeleid op middellange termijn. Rotterdam: KPVV.

Stradling, S. 2007. Determinants of Car Dependence. Transport Research Institute. Edinburgh: Napier University.

Tayal, T., K. Anantuni, and E. Burns. 2001. Measuring Auto Dependence in Metro Phoenix using GIS. Tampa: Arizona State University.

Urry, J. 2004. The system of automobility. Theory, Culture and Society 21 (4/5): 25-40.

Van Acker, V., F. Witlox, and B. van Wee. 2010. When transport geography meets social psychology: Towards a new conceptual model of travel behaviour. Transport Reviews 30(2): 219-240.

Van de Coevering, P. 2013. Mobiliteit en ruimte in de hedendaagse stedelijke regio. In: Mobiliteit en Ruimte, de wisselwerking tussen mobiliteit en ruimte in de stedelijke regio. Ede: CROW, 50-65.

Van Til, R. J., L. Groenemeijer, C. Poulus, and R. Lukey. 2007. Discussienotitie Planning for Decline. Groningen: Provincie Groningen.

van Wee, B. 2013. Land use and transport. In The Transport System and Transport Policy. Cheltenham: Edward Elgar Publishers. 78-100.

- 2009. Self-selection: a key to a better understanding of location choices, travel behaviour, and transport externalities? Transport Reviews 29(3).

van Wee, B. and J. A. Annema. 2013. The Transport System and Transport Policy. Cheltenham: Edward Elgar Publishers.

Wegener, M. and F. Furst. 1999. Land Use Transport Interaction: State of the Art. Dortmund: IRPUD. 